\title{
Pathogenic Mutation of Spastin Has Gain-of-Function Effects on Microtubule Dynamics
}

\author{
Joanna M. Solowska, ${ }^{1}$ Mitchell D’Rozario, ${ }^{2}$ Daphney C. Jean, ${ }^{1}$ Michael W. Davidson, ${ }^{3}$ Daniel R. Marenda,,${ }^{1,2 *}$ \\ and Peter W. Baas ${ }^{1 *}$ \\ ${ }^{1}$ Department of Neurobiology and Anatomy, Drexel University College of Medicine, Philadelphia, Pennsylvania 19129, ${ }^{2}$ Department of Biology, Drexel \\ University, Philadelphia, Pennsylvania 19104, and ${ }^{3}$ National High Magnetic Field Laboratory, Florida State University, Tallahassee, Florida 32310
}

\begin{abstract}
Mutations to the SPG4 gene encoding the microtubule-severing protein spastin are the most common cause of hereditary spastic paraplegia. Haploinsufficiency, the prevalent model for the disease, cannot readily explain many of its key aspects, such as its adult onset or its specificity for the corticospinal tracts. Treatment strategies based solely on haploinsufficiency are therefore likely to fail. Toward developing effective therapies, here we investigated potential gain-of-function effects of mutant spastins. The full-length human spastin isoform called M1 or a slightly shorter isoform called M87, both carrying the same pathogenic mutation C448Y, were expressed in three model systems: primary rat cortical neurons, fibroblasts, and transgenic Drosophila. Although both isoforms had ill effects on motor function in transgenic flies and decreased neurite outgrowth from primary cortical neurons, mutant M1 was notably more toxic than mutant M87. The observed phenotypes did not result from dominant-negative effects of mutated spastins. Studies in cultured cells revealed that microtubules can be heavily decorated by mutant M1 but not mutant M87. Microtubule-bound mutant M1 decreased microtubule dynamics, whereas unbound M1 or M87 mutant spastins increased microtubule dynamics. The alterations in microtubule dynamics observed in the presence of mutated spastins are not consistent with haploinsufficiency and are better explained by a gain-offunction mechanism. Our results fortify a model wherein toxicity of mutant spastin proteins, especially mutant M1, contributes to axonal degeneration in the corticospinal tracts. Furthermore, our results provide details on the mechanism of the toxicity that may chart a course toward more effective treatment regimens.
\end{abstract}

Key words: axon; degeneration; hereditary spastic paraplegia; microtubule; spastin

\section{Introduction}

Mutations in the SPG4 gene, which encodes for an enzyme called spastin, is the chief cause of hereditary spastic paraplegia (HSP) (Hazan et al., 1999). Autosomal dominant HSP-SPG4 is most usually adult onset, with progressive degeneration of axons occurring mainly within the corticospinal tracks. Genetic analyses have led to the view that haploinsufficiency is the molecular mechanism of the disease. In this view, axonal degeneration in HSP results from insufficient levels of spastin (Fonknechten et al., 2000; Lindsey et al., 2000). The haploinsufficiency model is buoyed by the fact that most of the $>200$ pathogenic mutations

Received Aug. 1, 2013; revised Dec. 10, 2013; accepted Dec. $22,2013$.

Author contributions: J.M.S., D.R.M., and P.W.B. designed research; J.M.S., M.D., D.C.J., and D.R.M. performed research; M.W.D. contributed unpublished reagents/analytic tools; J.M.S., D.R.M., and P.W.B. analyzed data; J.M.S. and P.W.B. wrote the paper.

This work was supported by National Science Foundation Grant 1050841245 and National Institutes of Health Grants R01 NS28785 and R56 NS028785 to P.W.B.; National Science Foundation Grant IOS1256114 and National Institutes of Health GrantR21 RR026074 to D.R.M.; Philadelphia Institute of Neurodegenerative Diseases grants to P.W.B. and D.R.M.; the Pennsylvania Department of Health CURE program to Drexel University College of Medicine; and the Brody Family Medical Trust postdoctoral fellowship to D.C.J.

The authors declare no competing financial interests.

*D.R.M. and P.W.B. contributed equally to this work as senior authors.

Correspondence should be addressed to Dr. Peter W. Baas, Department of Neurobiology and Anatomy, 2900 Queen Lane, Philadelphia, PA 19129. E-mail: pbaas@drexelmed.edu.

DOI:10.1523/JNEUROSCI.3309-13.2014

Copyright $\odot 2014$ the authors $\quad 0270-6474 / 14 / 341856-12 \$ 15.00 / 0$ in SPG4 are nonsense or frameshift mutations, many of which would theoretically lead to mRNAs that undergo nonsensemediated decay (Bürger et al., 2000). Proponents of the model also point to the lack of detection of any truncated spastins in studies to date on human patients (Riano et al., 2009). However, there remain concerns about a model based exclusively on haploinsufficiency, especially because such a model offers no compelling explanation for why the disease is typically adult onset or why degeneration occurs mainly in the corticospinal tracts.

Spastin is a microtubule-severing ATPase that breaks longer microtubules (MTs) into shorter ones (Errico et al., 2002; Evans et al., 2005, Roll-Mecak and Vale, 2005). Severing regulates the number and mobility of MTs and the distribution of their plus ends (Baas et al., 2006) and may functionally link MT-severing to certain aspects of membrane trafficking (Allison et al., 2013). Studies on Drosophila and zebrafish indicate that experimental reductions of spastin can be harmful to axonal development (Sherwood et al., 2004; Trotta et al., 2004; Wood et al., 2006), but developmental abnormalities have not been observed in homozygous spastin knock-out mice (Tarrade et al., 2006; Kasher et al., 2009) or human patients with one inactive spastin allele. In addition, genetic analyses of HSP-SPG4 patients have not revealed a correlation between spastin levels and the severity of neurodegenerative symptoms (Yip et al., 2003, Shoukier et al., 
2009), and there are even rare HSP patients with mutations in the SPG4 gene that are not function-blocking (Solowska et al., 2010).

SPG4 has two start codons that produce two spastin isoforms called M1 and M87 (Claudiani et al., 2005). M1 is only detectably present in the adult spinal cord, whereas M87 (M85 in rodents) is ubiquitous (Solowska et al., 2008). Our earlier studies using truncated GFP-tagged mouse spastins showed that M1 has detrimental effects on neurite outgrowth and axonal transport, whereas M85 does not. However, most likely to produce neurotoxic proteins are missense mutations found in full-length spastin. Here we present functional studies on individually expressed untagged human M1 and M87 isoforms carrying the inactivating C448Y mutation found in some HSP-SPG4 patients (Hazan et al., 1999; Fonknechten et al., 2000). Our results support a model based on toxic gain-of-function effects of mutant spastins, especially M1, and implicate the MTs themselves as a chief target of the mutant spastin toxicity. These observations have strong implications for patient therapy.

\section{Materials and Methods}

Spastin constructs. The full-length WT human spastin cDNA with 221 nucleotides of 5'UTR was prepared as described previously (Solowska et al., 2008, 2010). To generate point mutation c.1343G $>$ A leading to C448 $>$ Y amino acid change in spastin AAA domain, the QuikChangell XL Site-Directed Mutagenesis Kit (Stratagene) was used according to the manufacturer's instructions. The presence of the mutations was confirmed by DNA sequencing. The nomenclature of the mutations refers to the cDNA sequence (GenBank NM_014946) with the A of the M1 translation initiation codon as +1 . The full-length WT or mutated C448Y cDNA was used to prepare Group I constructs simultaneously expressing M1 and M87 spastin isoforms in transfected cells. To create Group II constructs expressing only WT or C448Y M1 spastin isoforms (amino acids 1-616), the 5'UTR was deleted and the imperfect Kozak's sequence tgaATGa surrounding M1 start codon was replaced by good consensus Kozak's sequence accATGa, using site-directed mutagenesis. To prepare Group III constructs expressing only M87 isoforms (amino acids 87616), the N-terminal part encoding the first 86 amino acids was deleted and a good Kozak's sequence accATGg surrounding M87 start codon was created by site-directed mutagenesis. Human spastin cDNAs were cloned into the pUAST vector for spastin expression in Drosophila, into pCMV vector (Stratagene) for transient expression in primary cortical neurons, into pTRE-Tight vector with doxycycline (Dox)-inducible promoter (Clontech) for stable, inducible expression of spastin proteins in cultured fibroblasts, or into a bicistronic pIRES2 DsRed-Express2 vector (Clontech) that allows for the simultaneous expression of red fluorescent protein (RFP) and untagged mutated spastins. For live-cell imaging of MT dynamics, tdEos-tubulin-C-18 vector encoding $\alpha$-tubulin tagged with Eos fluorescent protein was prepared by substituting mEmerald-tubulin cDNA with tdEos cDNA in EGFP C1 vector (Clontech).

Drosophila stocks and genetics. The GAL4/UAS system was used to generate stable transgenic lines of Drosophila expressing spastin isoforms. All crosses and stocks were maintained at $25^{\circ} \mathrm{C}$ using standard cornmeal, yeast, and molasses food. Spastin M1 and M87 constructs were cloned into pUAST (UAS:M1 C448Y and UAS:M87 C448Y), and stable transgenic animals were created by BestGene (www.thebestgene.com) using company protocols. The GAL4/UAS system (Brand and Perrimon, 1993) was used to overexpress transgenic Drosophila spastin isoforms. $P\left\{\right.$ GawB elav $^{C 155}$ (Bloomington Stock Center \#458) was used to drive transgene expression of spastin constructs pan-neuronally and is abbreviated in the text as ELAV. ELAV-Gal4, UAS:M1 C448Y, and UAS:M87 C448Y were outcrossed to $w^{1118}$ (Bloomington Stock Center \#3605) for outcrossed controls. ELAV-Gal4 was crossed to either UAS:M1 C448Y or UAS:M87 C448Y for experimental flies.

Drosophila behavioral analysis. All behaviors were digitally recorded using a Sony DCR-SR47 Handycam with Carl Zeiss optics. Subsequent digital video analysis was quantified using iMovie software (Apple).
For the loss of righting reflex, a modified version of the method described by Leal and Neckameyer (2002) was performed. Adult flies (males and females) of the appropriate genotype were collected 2-6 h after eclosion. On day 2, flies were individually placed into a supine position and the amount of time for the fly to right itself in an upright position was quantified. Each trial was repeated 3 times. The average time for the fly to right itself was calculated for each genotype. To determine the significance between multiple different genotypes, a one-way ANOVA analysis was performed with Tukey post hoc analysis.

For climbing ability, a modified version of the assay described by Le Bourg and Lints (1992) was used. Flies were collected between 0 and $8 \mathrm{~h}$ after eclosion and assayed every $2 \mathrm{~d}$ from days 0 to 10 . Groups of 10 flies were transferred to a clean, empty vial and given $18 \mathrm{~s}$ to climb $5 \mathrm{~cm}$, as described previously (Melicharek et al., 2010). Each trial was repeated 3 times. To determine the significance between multiple different genotypes, ANOVA was performed with Tukey post hoc analysis.

Generation of the stable, inducible cell lines expressing spastins. RFL-6 (rat fibroblasts) cells were transfected with pTet-On Advanced vector (Clontech) encoding the tetracycline-controlled transcriptional transactivator, using Lipofectamine 2000 (Invitrogen) as recommended by the manufacturer. Colonies of stable transfected cells were selected in medium with $0.4 \mathrm{mg} / \mathrm{ml} \mathrm{G418} \mathrm{(Cellgro)} \mathrm{and} \mathrm{tested} \mathrm{for} \mathrm{induction} \mathrm{of} \mathrm{GFP} \mathrm{by}$ doxycycline (Dox, Clontech), using GFP cloned into pTRE-Tight vector (Clontech). Cell clones with the highest induction levels of GFP were further subcloned using limited dilution culturing. The best RFL-6/ Tet-On subclone was expanded and transfected with spastin constructs in pTRE-Tight vector carrying the tetracycline response element and with a linear hygromycin marker (Clontech). Double-stable cell lines TRE/M87WT (expressing WT M87 isoform), TRE/M87CY (expressing M87 isoform with C448Y mutation), and TRE/M1CY (expressing M1 isoform with C448Y mutation) were selected using $0.1 \mathrm{mg} / \mathrm{ml}$ hygromycin (Clontech) and $0.2 \mathrm{mg} / \mathrm{ml} \mathrm{G} 418$ in F-12K medium (Invitrogen) with $10 \%$ tetracycline-free FBS (Clontech). Dox-inducible spastin expression was tested by Western blotting with rabbit polyclonal anti-spastin $\mathrm{Sp} /$ AAA antibody as described previously (Solowska et al., 2008). Cloned cells with the highest levels of spastin expression in response to $1 \mu \mathrm{g} / \mathrm{ml}$ Dox over $18 \mathrm{~h}$ and no expression without Dox were further subcloned using limited dilution culturing.

Immunostaining of cultured cells. To express spastins, stable transfected TRE/M87WT, TRE/M87CY, and TRE/M1CY cells were cultured in medium with $0.5-2 \mu \mathrm{g} / \mathrm{ml}$ Dox over $18 \mathrm{~h}$. Primary rat cortical neurons were cultured and transfected with mutated M1 or M87 spastin cDNA in pCMV vector (Stratagene) using the Amaxa nucleofector and an approach identical to that which we have used previously for cultured rat hippocampal neurons (Yu et al., 2005). For immunofluorescence studies, cells were fixed with $4 \%$ paraformaldehyde in PBS, and then postextracted with $0.1 \%$ Triton $\mathrm{X}-100$. The cultures were then double-labeled by exposure first to anti-spastin SP5 polyclonal antibody, overnight at $4^{\circ} \mathrm{C}$, and then to AlexaFluor-488-conjugated goat-anti-rabbit (Invitrogen) and Cy3-conjugated $\beta$-tubulin mouse monoclonal antibody (Sigma) for $1 \mathrm{~h}$ at $37^{\circ} \mathrm{C}$. Rabbit polyclonal anti-spastin SP5 antibody was generated using a 92-285 amino acid fragment of human spastin as described previously (Solowska et al., 2008). Double-label overlay images were obtained with a Zeiss Pascal LSM 5 confocal microscope. The brightness and contrast of images in the same experiment were adjusted in identical manner using Adobe Photoshop.

Quantification of MT levels. Images of MTs in control cells or cells expressing spastins, as indicated by double-staining with anti-spastin and anti-tubulin antibodies, were obtained with an Axiovert 200 microscope (Carl Zeiss) equipped with a high-resolution CCD (Orca ER, Hamamatsu) using identical imaging criteria, such as gain and exposure time. Mean gray values of tubulin fluorescence (the sum of gray values of all the pixels in a selected cell divided by the number of pixels) were obtained using AxioVision software and presented as arbitrary fluorescence units (AFU). For each experimental condition, fluorescence intensity was measured in no $<30$ cells. Statistics were done using unpaired two-tailed Student's test and Microsoft Excel software.

Nocodazole treatment. Control, nonexpressing RFL-6/Tet-On cells or stably transfected TRE/M87CY and TRE/M1CY cell lines were cultured 
with $2 \mu \mathrm{g} / \mathrm{ml}$ Dox over $18 \mathrm{~h}$ to induce moderate expression of mutated spastin isoforms. To express mutated spastins at high levels, RFL-6/ Tet-On cells were transiently transfected with pTRE/M87CY or pTRE/M1CY constructs, and cultured with $0.5 \mu \mathrm{g} / \mathrm{ml}$ Dox over $18 \mathrm{~h}$. Then control cells and spastin-expressing cells were cultured in medium with Dox and $2 \mu \mathrm{g} / \mathrm{ml}$ nocodazole (Sigma) for $15 \mathrm{~min}$ at $37^{\circ} \mathrm{C}$. To evaluate MT depolymerization, one set of nocodazole-treated cells was fixed, doublestained with anti-tubulin and anti-spastin antibodies, and used to measure MT levels as described above. The second set of nocodazoletreated cells was rinsed with nocodazole-free medium and cultured without nocodazole for $20 \mathrm{~min}$ at $37^{\circ} \mathrm{C}$. MT repolymerization was then evaluated in fixed and immunostained control and spastin-expressing cells.

Analysis of MT dynamics. For visualization of MT polymerization and depolymerization in the presence of mutated spastin isoforms, RFL-6 cells were cotransfected with pIRES2 DsRed-Express2/M87 C448Y (Red/M87 CY) or pIRES2 DsRed-Express2/M1 C448Y (Red/ M1 CY) and tdEos-tubulin-C-18 vectors. tdEos fluoresces green and can be photoconverted to fluoresce red, but we did not exploit its photoconversion properties for the present studies; rather, we used it without photoconversion (i.e., only in the green channel), and we did so because we found that tdEos tubulin incorporates more thoroughly into the MT array than EGFP tubulin. Immunostaining with anti-spastin antibody confirmed that cells expressing RFP also expressed spastins. At 18-22 $\mathrm{h}$ after transfection, images of 8-15 doubletransfected cells were captured at $30 \mathrm{~s}$ intervals for $120 \mathrm{~s}$ at $37^{\circ} \mathrm{C}$ using AxioVision 4.6. The growth and shortening of 15-20 individual MTs per cell were tracked and measured using AxioVision 4.6 software. Statistics were done using unpaired two-tailed Student's test and Microsoft Excel software. Cells transfected with M1 C448Y were fixed and immunostained with anti-spastin antibody to determine postmortem, whether mutated M1 was aggregated or decorating MTs in the cells that had been used for live-cell imaging.

\section{Results}

Human spastin isoforms M1 and M87 with pathogenic mutation C448Y interact differently with MTs and affect neurite outgrowth to different degrees

The first start codon in the SPG4 open reading frame is surrounded by a Kozak's sequence deviating significantly from the consensus motif with neither the purine in position -3 nor the guanine in position +4 (Kozak, 2002). This leads to a leaky scanning of the first AUG and preferred initiation of translation at the second AUG with a guanine in position +4 . As a result, a $68 \mathrm{kDa}$ isoform called M1 and a $60 \mathrm{kDa}$ isoform called M87 (M85 in rodents) are synthesized (Claudiani et al., 2005; Solowska et al., 2008). Our earlier studies in rodents demonstrated that M85 is the predominant spastin isoform in all tissues at all stages of development analyzed, whereas M1 is only detectably present in adult spinal cord, the location of the corticospinal tracts (Solowska et al., 2008). Similarly, we detected M87 spastin expression both in adult human cerebral cortex and spinal cord, whereas a significant level of M1 was detected only in adult human spinal cord and not brain (Solowska et al., 2010). This observation raised the question as to whether human mutated M1 and M87 differ in their functional properties relevant to the degeneration of axons specifically in corticospinal tracts. To address this question, we prepared Group I spastin constructs carrying endogenous Kozak's sequences, Group II constructs in which endogenous imperfect M1 Kozak's sequence tgaATGa was replaced by a good Kozak's sequence accATGa, and Group III constructs in which the region encoding the first 86 spastin amino acids was deleted and the endogenous M87 Kozak's sequence ctcATGg was replaced by the perfect Kozak's sequence accATGg (Fig. 1A). We generated wild-type (WT) constructs as well as constructs with the pathogenic missense mutation C448Y found in HSP-SPG4 patients (Hazan et al., 1999; Fonknechten et al., 2000). The C448Y mutation is located in spastin's AAA domain responsible for MT-severing activity (Fig. $1 A, B$ ). We deliberately prepared constructs encoding untagged spastins to avoid any nonspecific effects that tagging might have on spastin configuration and activity.

All spastin cDNAs were cloned into pTRE-Tight vector that contains the tetracycline response element (TRE) and were used 

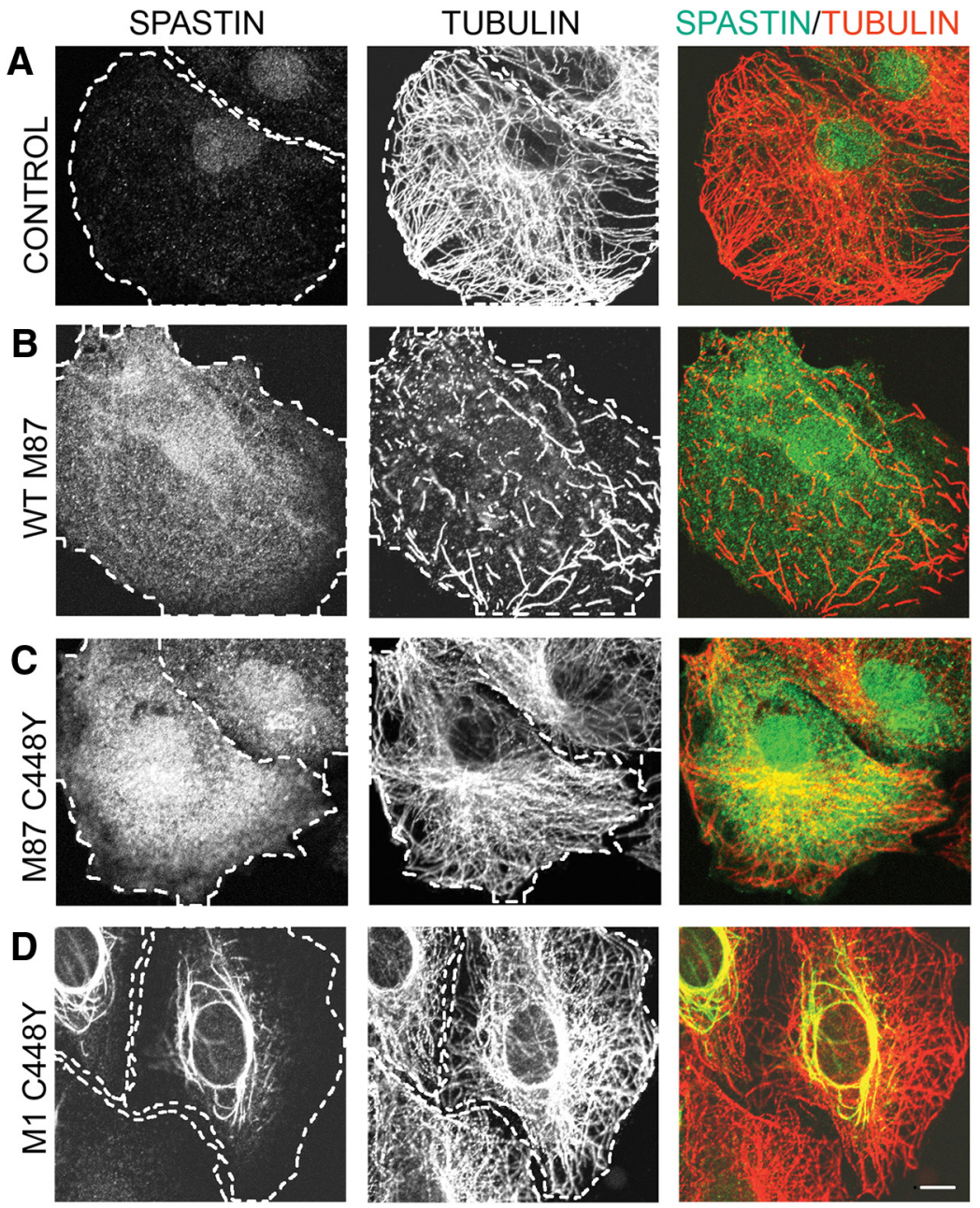

Figure 2. Mutated C448Y spastin isoforms do not sever MTs. Control RFL-6/Tet-0n cells and stably transfected TRE/M87 WT, TRE/M87 CY, or TRE/M1 CY cells were cultured in medium with $2 \mu \mathrm{g} / \mathrm{ml}$ Dox for $18 \mathrm{~h}$. After fixation, cells were stained with anti-spastin and anti-tubulin antibodies. $A$, Control RFL-6/Tet-0n cells cultured with Dox did not express spastin as indicated by immunostaining with anti-spastin antibody and MTs were not severed as indicated by staining with anti-tubulin antibody. $\boldsymbol{B}$, Moderate levels of WT M87 spastin expressed in TRE/M87 WT cells exposed to Dox were sufficient to sever all MTs. C, High levels of mutated M87 spastin were synthesized in TRE/M87 CY cells grown in medium with Dox, but MTs were not severed even in the regions of very high M87 accumulation. D, MTs in TRE/M1 CY cells expressing mutated M1 after Dox treatment were also not severed, but mutated M1 clearly decorated a subset of MTs around the nucleus. Scale bar, $10 \mu \mathrm{m}$.

for transfection of RFL-6 rat fibroblasts stably expressing the Tet-On transactivator (RFL-6/Tet-On cells). In the presence of Dox, Tet-On transactivator binds to the TRE and produces inducible transcription of the downstream gene. As predicted, in cells transfected with constructs carrying the endogenous Kozak's sequences, both spastin isoforms were expressed simultaneously as a result of leaky scanning of the first AUG, and the majority of spastin was expressed as M87 (Fig. 1C; Group I). The replacement of the imperfect M1 Kozak's sequence by a good Kozak's sequence in Group II constructs led to almost exclusive expression of the M1 isoform (Fig. 1C; Group II), whereas cells transfected with Group III constructs exclusively expressed the M87 isoform (Fig. 1C; Group III). The expression of spastin was only detected in transfected cells cultured in the presence of Dox. After $18 \mathrm{~h}$ of exposure to $0.5 \mu \mathrm{g} / \mathrm{ml}$ Dox, the mutated spastins did not accumulate to significantly higher levels than their WT counterparts. However, when start codons of both isoforms had equally good Kozak's sequences allowing equally efficient translation, WT and mutated $\mathrm{M} 1$ always accumulated significantly more than corresponding M87 (Fig. 1C).
To test how C448Y mutation that is located in pore loop 2 of the AAA domain and does not destroy spastin ATPase activity (White et al., 2007) affects spastin MT-severing activity, we generated stably transfected cell lines that express WT M87 spastin (TRE/M87WT cells) as well as stably transfected cell lines that express M87 C448Y spastin (TRE/M87CY cells) or M1 C448Y spastin (TRE/M1CY cells) under control of Dox-inducible promoter. MT levels and organization in control RFL-6/ Tet-On cells that do not express spastins when cultured with Dox are shown in Figure $2 A$. Immunostaining of TRE/M87WT cells with anti-spastin antibody revealed that even moderate levels of WT M87 spastin, synthesized after $18 \mathrm{~h}$ exposure to $0.5 \mu \mathrm{g} / \mathrm{ml}$ Dox, are sufficient to sever all MTs (Fig. 2B). To determine whether M87 C448Y spastin has any residual MTsevering activity, the TRE/M87CY cells were grown in medium with $2 \mu \mathrm{g} / \mathrm{ml}$ Dox for $18 \mathrm{~h}$. As a result, high levels of M87 C448Y were synthesized, but MTs were not severed even in regions of high spastin accumulation (Fig. 2C). MTs in TRE/ M1CY cells expressing M1 C448Y after $18 \mathrm{~h}$ treatment with $2 \mu \mathrm{g} / \mathrm{ml}$ Dox were also not severed, and mutated M1 clearly decorated a subset of MTs around the nucleus (Fig. 2D).

As differences in the interaction of C448Y spastin isoforms with MTs might be functionally important, we wished to determine whether such differences could also be observed in neuronal cells. To test that possibility, we transfected primary rat cortical neurons with mutated spastin cDNAs in pCMV vector. pTRE constructs cannot readily be used in nondividing primary neurons because, unlike fibroblasts, nondividing cells cannot be stably transfected to synthesize the TET-On transactivator. At $48 \mathrm{~h}$ after transfection, cells were fixed and stained with anti-spastin and anti-tubulin antibodies. In neuronal cells as in fibroblasts, diffuse M87 C448 staining was observed in the cell body. In axons, M87 was localized predominantly in proximal regions but also elsewhere and in distal regions (Fig. $3 A, B$ ). In cortical neurons transfected with mutated M1, M1 C448Y mostly colocalized with a subset of MTs around the nucleus and in proximal axon. No M1 C448Y staining was detected in the distal axon (Fig. 3C,D). This staining pattern indicates that decoration of some MTs by M1 C448Y is not limited to fibroblasts but also occurs in neuronal cells. As MT binding and interacting domains (MIT and MTBD) are exactly the same in mutated M1 and M87, the difference observed in their interaction with MTs must be attributed to the presence of the 86-amino acid $\mathrm{N}$-terminal fragment in mutated M1. Interestingly, however, WT M1 or M1-carrying mutations that do not affect MT-severing activity do not decorate MTs (Solowska et al., 2010). We therefore concluded that decoration of MTs requires both the presence of the highly hydrophobic 86 
N-terminal amino acids but also conformational changes in spastin caused by a mutation in the AAA domain.

Examination of transfected neuronal cells also revealed that expression of mutated spastins has a profound effect on neurite outgrowth. We analyzed a total of 217 control, 207 M1 C448Y, and 160 M87 C448Y neuronal cells in 6 separate dishes and calculated the percentage of cells with processes longer than $60 \mu \mathrm{m}$ (long processes) and the percentage of cells with processes shorter than $20 \mu \mathrm{m}$ (short processes). The analysis showed that expression of both mutated spastin isoforms significantly decreased the percentage of cells with long processes and significantly increased the percentage of cells with short processes compared with control, mock-transfected neuronal cells. However, the M1 C448Y also significantly decreased neurite outgrowth compared with M87 C448Y (Fig. 3E,F). These results indicate that, although expression of either M1 or M87 mutated spastin isoform can be detrimental, the effect of M1 is notably worse. We hypothesize that these ill effects of mutated spastin proteins have not been observed in developing CNS of HSPSPG4 patients carrying C448Y mutation because in vivo the levels of spastin are very strictly controlled at the transcriptional level by a tissue-specific promoter and at the translational level (particularly in the case of M1) by an inefficient Kozak's sequence. It seems reasonable to surmise that spastic paraplegia may develop either as a result of accumulation of mutated proteins to neurotoxic levels and/or long-term accumulating effects of low levels of mutated spastin.

\section{Expression of mutated M1 C448Y in transgenic Drosophila affects motor function more than expression of M87 C448Y}

We generated transgenic Drosophila expressing either M1 C448Y or M87 C448Y to test whether these two mutated spastin isoforms can affect motor function in vivo. To create transgenic flies, we cloned human spastin cDNA into the pUAST vector. Transgenes were expressed using the Gal4//UAS system (Brand and Perrimon, 1993). We used the ELAV-Gal4 pan-neural driver to limit expression of the transgenes specifically to postmitotic neurons in the CNS. We verified the expression of mutant M1 C448Y and M87 $\mathrm{C} 448 \mathrm{Y}$ in the transgenic flies by performing Western blot analysis on fly head lysates (Fig. 4A). Genetic analyses indicated that one copy of spastin cDNA encoding either M1 C448Y or M87 C448Y was inserted into Drosophila chromosome 3. However, the expression level of M1 C448Y was significantly higher than that of M87 C448Y. As identical promoters and Kozak's sequences controlled the expression of both isoforms, the differences in expression levels could be attributed either to a more favorable location
M87 C448Y

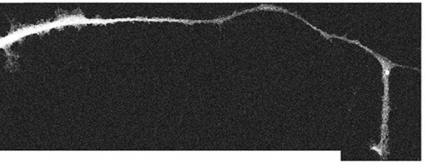

E Processes $>60 \mu \mathrm{m}$

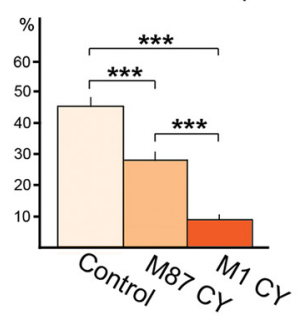

Distal

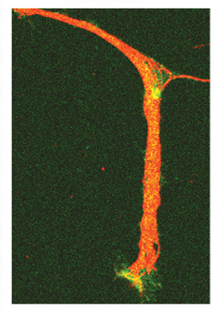

C $\mathrm{M} 1 \mathrm{C} 448 \mathrm{Y}$

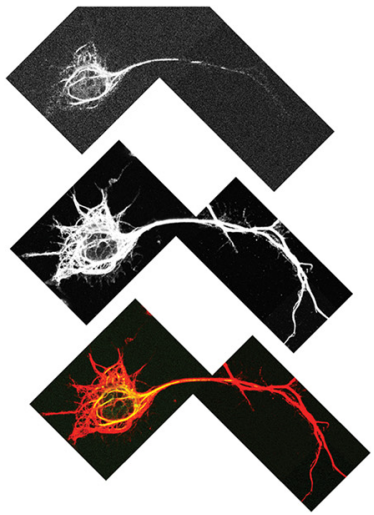

D

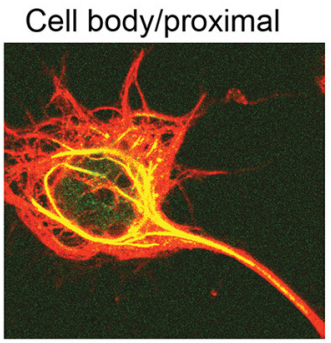

F Processes $<20 \mu \mathrm{m}$

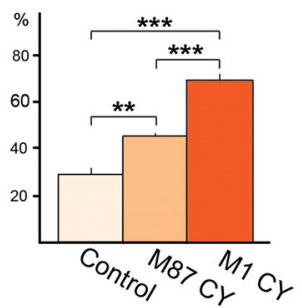

Figure 3. Mutant spastin isoforms are differently distributed in primary cortical neurons and impair neurite outgrowth to different degree. Primary cortical neurons were transfected with $\mathrm{pCMV} / \mathrm{M} 87 \mathrm{CY}$ or $\mathrm{pCMV} / \mathrm{M} 1 \mathrm{CY}$ constructs. At $48 \mathrm{~h}$ after transfecC448Y spastin was detected in neuronal cell bodies and axons. $\boldsymbol{B}$, The highest levels of diffused expression of M87 C448Y were observed in proximal axon, whereas lower levels were present in the cell body and distal axon. C, M1 C448Y, in transfected neuronal decorated a subpopulation of MTs. $E$, Quantitative analysis revealed that either of the mutated spastin isoforms significantly decreased the percentage of cells with long processes. The impact of mutated $M 1$ on neurite outgrowth was, however, significantly percentage of neuronal cells transfected with mutated spastin isoforms grew only very short processes, but the percentage of cells with short neurites was significantly higher for mutant M1 than mutant M87. Scale bars: $A, C, 5 \mu \mathrm{m} ; \boldsymbol{B}, \boldsymbol{D}, 10 \mu \mathrm{m}$. Values are mean \pm SEM. ${ }^{* *} p=0.003$ ( $t$ test). ${ }^{* *} p<0.0003$ ( $t$ test).

of M1 cDNA in the Drosophila genome or more likely to a lower degradation rate of mutated M1 protein compared with mutated M87 protein.

Control ELAV-Gal4 flies (Fig. 4B) and flies that express M87 C448Y did not show any significant postural defect (Fig. 4C), whereas flies that express M1 C448Y showed aberrant posture and held their wings abnormally apart from their body (Fig. 4D). The penetrance of this phenotype is $100 \%$. This result suggests that the presence of M1 C448Y has a more severe effect on posture than expression of M87 C448Y.

We next wished to determine whether expression of human mutant spastin in the nervous system of transgenic flies had a significant effect on the behavior of the animal. We expressed either M1 C448Y or M87 C448Y in the CNS of Drosophila and assayed motor reflex behavior through two different assays: the 

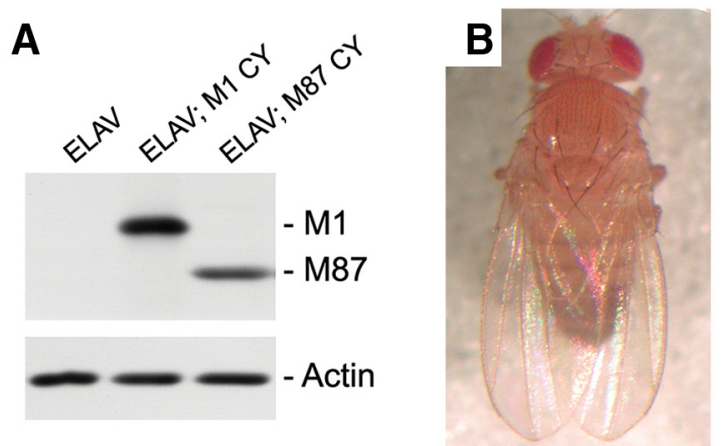

ELAV

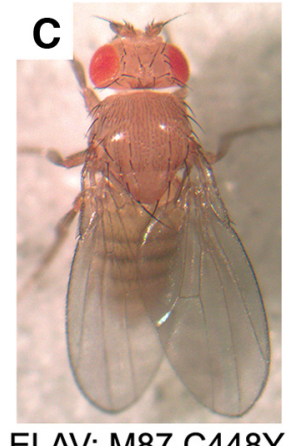

ELAV; M87 C448Y

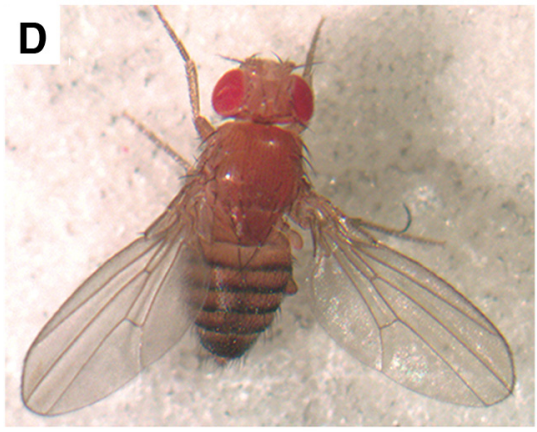

ELAV; M1 C448Y

Figure 4. Expression of human spastin M1 C448Y in Drosophila CNS results in a posture defect. $\boldsymbol{A}$, Proteins for Western blot analysis were extracted from 30 heads of adult control or experimental Drosophila and aliquots corresponding to 3 heads were used for SDS-PAGE. Antihuman spastin antibody SP/AAA did not react with Drosophila spastin in control ELAV-Gal4 flies but clearly detected expression of human M1 C448Y in ELAV-Gal4; UAS: M1 CY flies and expression of human M87 C448Y in ELAV-Gal4; UAS: M87 CY flies. Actin was used as a loading control. $\boldsymbol{B}$, Control nonexpressing flies ELAV-Gal4 and (C) experimental fly expressing human spastin M87 C448Y throughout the CNS did not exhibit posture defects. D, 100\% of experimental adult flies expressing human spastin M1 C448Y in CNS held their wing apart from the midline of the body.

loss of righting reflex assay (LORR) (Leal and Neckameyer, 2002) and the climbing assay (Le Bourg and Lints, 1992). LORR measures the time it takes adult flies to right themselves from a supine position, whereas the climbing assay measures whether a fly can vertically climb a set distance in a set amount of time. We observed that expression of either M87 C448Y or M1 C448Y significantly increased the righting time of flies (Fig. $5 A$ ) and reduced the climbing ability of experimental flies (Fig. $5 B$ ) compared with controls. These motor deficits were not caused simply by insertion of human spastin cDNA into the Drosophila genome because outcrossed UAS:M1 CY and UAS:M87 CY flies that did not express mutated spastins were behaviorally indistinguishable from ELAV-Gal4 control flies. LORR and climbing assays also revealed that the deficits in motor behavior were worse in flies expressing M1 C448Y compared with flies expressing M87 C448Y (Fig. 5). Further, the climbing assay demonstrated that over time the climbing ability deteriorates significantly faster in flies expressing M1 C448Y compared with flies expressing M87 C448Y in the CNS. At day 10 after eclosion, $\sim 100 \%$ of control flies passed the climbing test, compared with 70\% of M87 C448Y expressing flies and $0 \%$ of flies expressing M1 C448Y (Fig. 5B). Together, our results indicate that, although expression of either M87 C448Y or $\mathrm{M} 1 \mathrm{C} 448 \mathrm{Y}$ is deleterious to fly motor behavior, expression of M1 C448Y affects motor function more severely than expression of M87 C448Y.

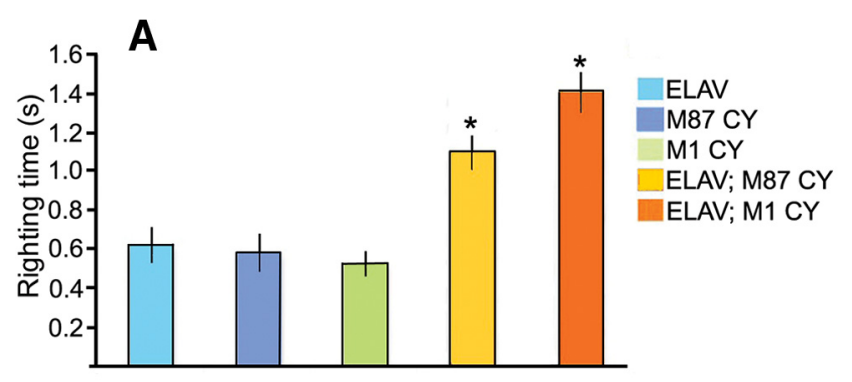

B

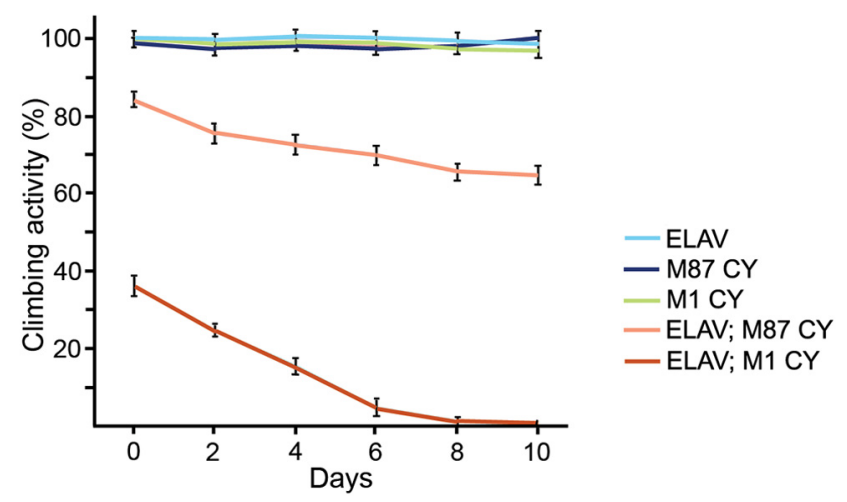

Figure 5. Expression of mutated human spastin isoforms in Drosophila CNS affects motor behavior. $\boldsymbol{A}$, The average time for mutated spastin-expressing experimental flies ELAV-Gal4; UAS:M87 CY (ELAV; M87 CY) and ELAV-Gal4; UAS: M1 CY (ELAV; M1 CY) to right themselves from a supine position was significantly longer compared with control Elav-Gal4 (ELAV) flies and outcrossed UAS:M87 C448Y (M87 CY) and UAS:M1 C448Y (M1 CY) flies that did not express mutated spastins. Values are mean \pm SEM. ${ }^{*} p<0.001$ (ANOVA). $n=10-13 . B$, The climbing ability of experimental flies ELAV; M87 CY and ELAV; M1 CY was significantly and progressively lower compared with control Elav-Gal4 flies and outcrossed UAS: M87 C448Y and UAS:M1 C448Y that did not express mutated spastins. The climbing ability of M1 CY-expressing flies was at all time points significantly lower compared with M87 CY-expressing flies. No significant decline in climbing activity was found in 10-d-old control Elav-Gal4 flies and outcrossed M87 CY and M1 CY flies. Values are mean $\pm \mathrm{SEM}$.

\section{Spastin isoforms carrying C448Y mutation do not exhibit dominant-negative activity}

We showed earlier that the C448Y mutation obliterates spastin MT-severing activity (Fig. 2). Therefore, the impaired neurite outgrowth observed in cultured primary cortical neurons or motor function deficits observed in transgenic flies cannot be explained by excessive MT severing inflicted by the ectopically expressed mutated spastin. As neural knockdown of Dspastin (endogenous fly spastin) in Drosophila results in impaired locomotor activity similar to the one we observed in transgenic flies expressing mutated spastins (Orso et al., 2005), we wished to test whether spastin isoforms carrying the $\mathrm{C} 448 \mathrm{Y}$ mutation gained a dominant-negative activity that impairs MT severing by the WT spastin. To sever MTs, spastin assembles into hexamers (White et al., 2007; Roll-Mecak and Vale, 2008). Spastin molecules with the C448Y mutation might interact with WT spastin molecules and prevent them from forming hexamers or the hexamers made of $\mathrm{C} 448 \mathrm{Y}$ and WT spastin molecules might be inactive. Full-length mutated spastins, such as $\mathrm{C} 448 \mathrm{Y}$, might also block interactions of WT spastin with MTs that are necessary for severing.

To test whether mutated spastin isoforms can inhibit the MTsevering activity in dominant-negative fashion, we used TRE/ M87WT cells. Cultured without Dox, TRE/M87WT cells did not express detectable spastin, as indicated by anti-spastin antibody staining and their MTs were not detectably severed as shown by 

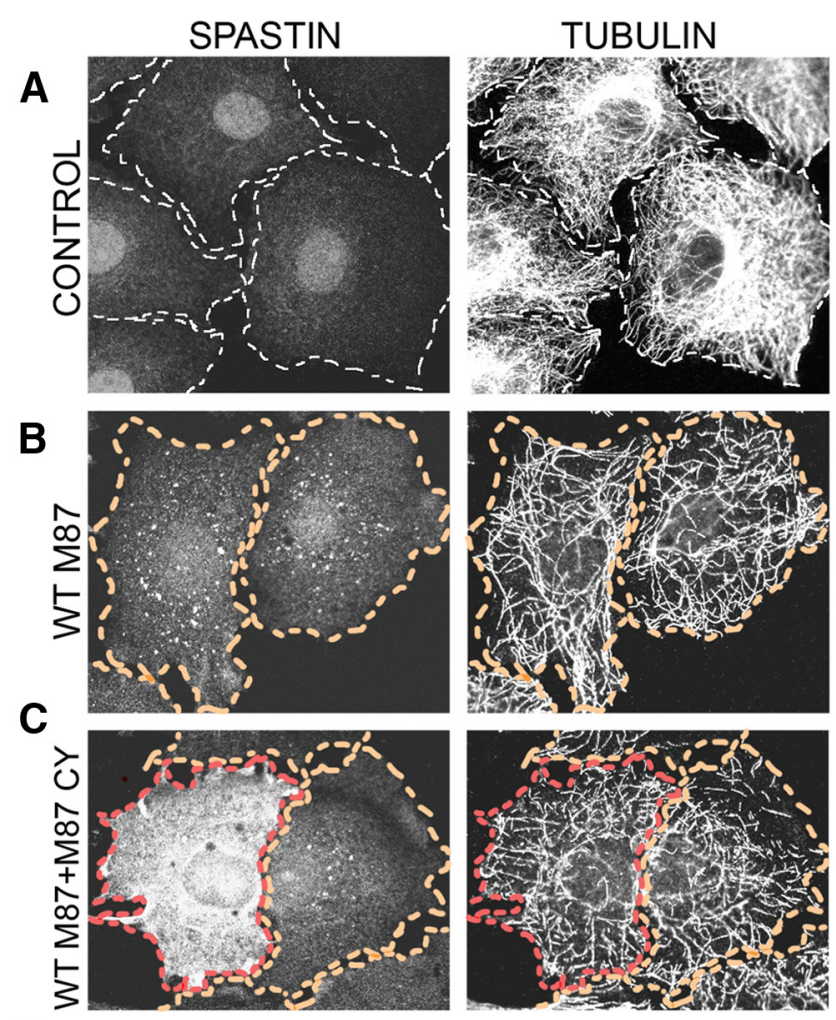

D
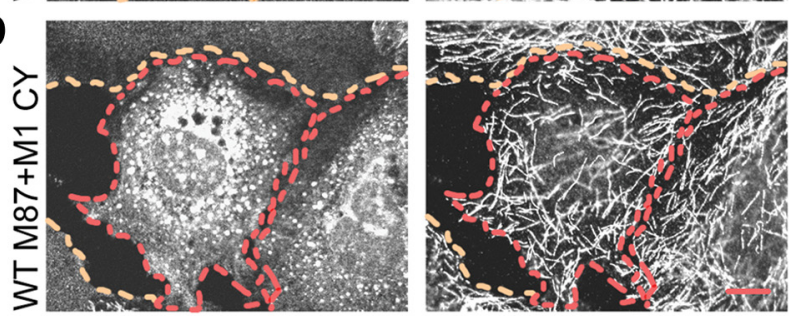

E

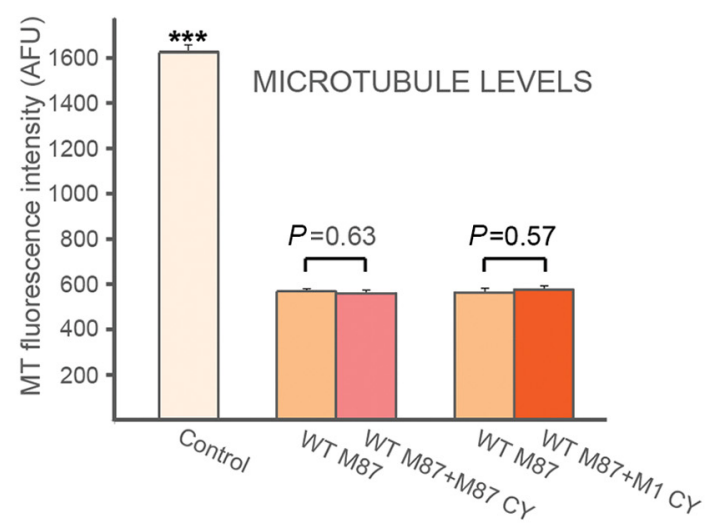

Figure 6. MM87 or M1 C448Y mutants do not affect MT-severing activity of WT M87. TRE/ M87WT cells were used for transient transfections with pTRE/M87CY or pTRE/M1CY. Antispastin antibody was used to evaluate levels of spastin in TRE/M87WT cells cultured with or without Dox as well as in cells coexpressing WT and mutated spastin isoforms. The fluorescence intensity after staining with anti-tubulin antibody was used to quantify MT levels. A, No spastin expression and MT severing was detected in TRE/M87WT cells cultured without Dox. $\boldsymbol{B}$, The $18 \mathrm{~h}$ exposure to $0.5 \mu \mathrm{g} / \mathrm{ml}$ Dox results in moderate WT M87 expression in $>90 \%$ of TRE/M87WT cells (outlined in yellow). $C$, The level of MT-severing in cells coexpressing WT M87 and M87 C448Y (outlined in red) is indistinguishable from those in cells that express only WT M87 (outlined in yellow). D, MT severing was not diminished in cells coexpressing WT M87 and M1 C448Y (outlined in red). $\boldsymbol{E}$, Compared with control nonexpressing cells, MT severing significantly lowered tubulin fluorescence intensity in cells expressing WT M87 alone or together with the mutant M87 or M1. Quantitative analysis of tubulin fluorescence intensity revealed comparable anti-tubulin antibody staining (Fig. 6A). After $18 \mathrm{~h}$ of exposure to $0.5 \mu \mathrm{g} / \mathrm{ml}$ Dox, moderate levels of WT M87 spastin sufficient to inflict significant severing and loss of MTs were detected in $>90 \%$ of TRE/M87WT cells (Fig. $6 \mathrm{~B}$, outlined in yellow). The TRE/M87WT cells were used for transient transfection with pTRE/M87 C448Y or pTRE/M1 C448Y constructs. After transfection, cells were cultured in medium with $0.5 \mu \mathrm{g} / \mathrm{ml}$ Dox for $18 \mathrm{~h}$ and then fixed and stained with anti-spastin and anti-tubulin antibodies. Cells coexpressing both WT and mutated spastin isoforms (Fig. 6C,D, outlined in red) were readily identified because of considerably higher intensity of immunostaining with antispastin antibody compared with cells expressing only WT M87 spastin (Fig. $6 C, D$, outlined in yellow). However, even the presence of mutated M87 or M1 at levels 2-4 times higher than that of WT M87 did not diminish MTs severing in double-expressing cells (compare MTs in double-expressing cells outlined in red and in cells expressing only WT M87 outlined in yellow in Fig. $6 C, D$ ). Although our results presented earlier (Figs. 2 and 3 ) indicate that mutated M1 decorates a subset of MTs, such colocalization does not seem to protect these MTs against severing as no intact MTs around the nucleus were found in cells coexpressing WT M87 and mutated M1 (Fig. 6D). Quantitative analysis of MT fluorescence intensity measured in groups of 30 cells for each experimental condition confirmed the results presented in Figure $6 A-D$. WT M87 spastin significantly reduced MT levels in expressing cells compared with control nonexpressing cells. However, MT levels were not significantly different in cells expressing WT M87 alone and in cells coexpressing WT M87 and M87 C448Y or M1 C448Y (Fig. 6E). This result indicates that the C448Y mutation does not endow the protein with dominantnegative properties.

\section{Mutated spastins affect MT dynamics in isoform-dependent fashion}

MTs are highly dynamic filaments made of tubulin polymers that experience stochastic episodes of growth and shortening at their plus-ends. Although a substantial fraction of the axonal MT array is notoriously stable, much of it remains highly dynamic and this is critical for the maintenance of the nervous system (Baas and Ahmad, 2013). Decreases in MT-severing caused by lower levels of active spastin would presumably result in lower numbers of MT plus-ends, and therefore in an overall decrease in MT dynamic events. However, reports of beneficial effects from treatments with vinblastine, at concentrations that would further decrease MT dynamics (Yang et al., 2010), in a Drosophila model of HSP-SPG4 (Orso et al., 2005) prompted us to revisit the issue of mutated spastin effects on MT dynamics. As we wished to test first the gross effects of mutated spastins on both depolymerization (shortening) and repolymerization (growth) of MTs, we chose to use a drug approach. Nocodazole, used in our experiments, binds to free tubulin subunits and prevents them from polymerizing into MTs. Therefore, in the presence of a sufficient concentration of nocodazole, MTs can only depolymerize, and as a result, MT loss is observed. Because binding of nocodazole to tubulin is reversible, removal of nocodazole allows MT

\section{$\leftarrow$}

level of MT loss in cells expressing WT M87 alone or coexpressing WT M87 and M87 C448Y or M1 C448Y. That result indicates that mutated spastin isoforms do not affect severing activity of coexpressed WT spastin. Scale bar, $15 \mu \mathrm{m}$. Values are mean \pm SEM. ${ }^{* * *} p<0.0001$ ( $t$ test). $n=30$. 

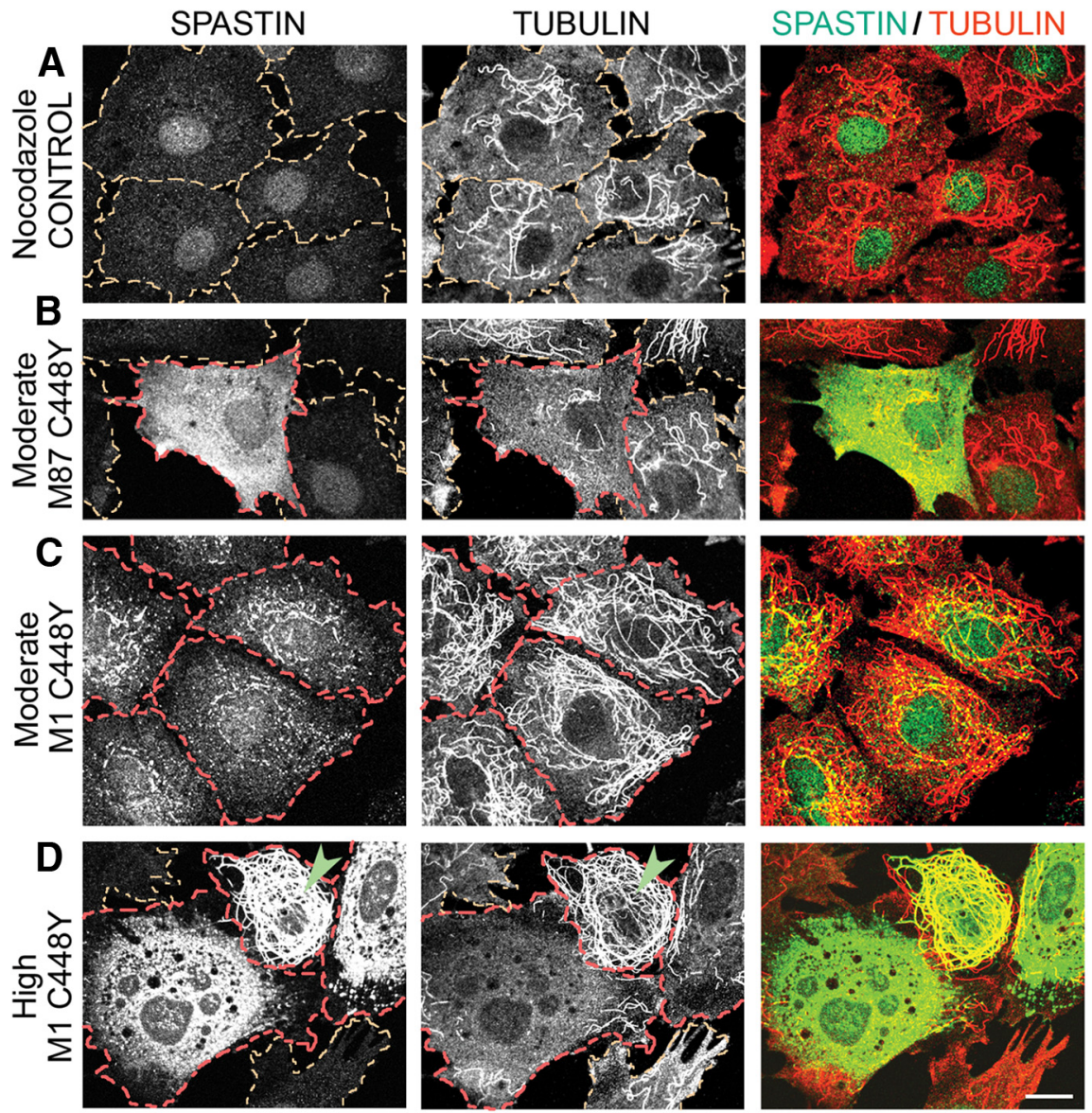

E
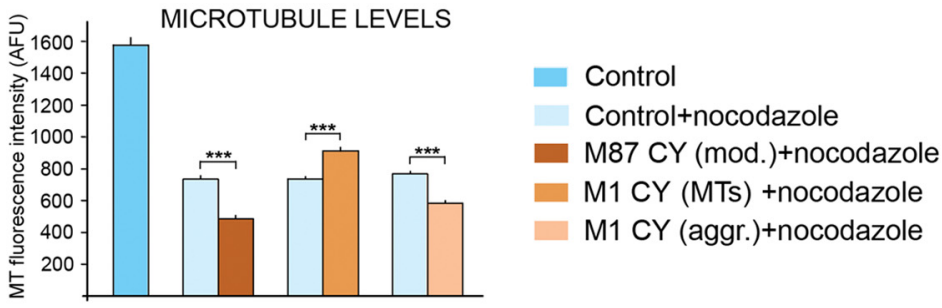

Figure 7. Expression of mutated spastin isoforms affects MT depolymerization. Control RFL-6/Tet-On cells and TRE/M87CY or TRE/M1CY cells were cultured in medium with $2 \mu \mathrm{g} / \mathrm{ml}$ Dox for $18 \mathrm{~h}$ and then for $15 \mathrm{~min}$ at $37^{\circ} \mathrm{C}$ in medium with $2 \mu \mathrm{g} / \mathrm{ml}$ nocodazole. After fixation, cells were immunostained with anti-spastin and anti-tubulin antibodies. $A$, In control nonexpressing cells (outlined in yellow), nocodazole treatment resulted in significant but not complete MT depolymerization revealed by staining with anti-tubulin antibody. $\boldsymbol{B}$, Moderate expression of M87 C448Y in TRE/M87CY cells (outlined in red) resulted in more complete depolymerization of MTs than that observed in nonexpressing cells (outlined in yellow). C, In cells expressing moderate levels of M1 C448Y colocalizing with MTs (outlined in red), the level of MT depolymerization was lower than in nonexpressing cells or in cells expressing M87 C448Y. D, In cells transiently transfected with PTRE/M1CY, M1 C448Y was expressed at high levels and either decorated MTs (e.g., a cell indicated by a green arrowhead) or formed aggregates (cells outlined in red). MTs decorated with mutated M1 spastin were very effectively prevented from depolymerization, whereas the presence of $\mathrm{M} 1$ aggregates resulted in nearly complete MT depolymerization. E, Quantification of MT levels in nocodazole-treated control nonexpressing cells and in cells expressing M87 C448Y or M1 $\mathrm{C} 448 \mathrm{Y}$ revealed that mutated M87 as well as aggregated mutated M1 significantly increased MT depolymerization, whereas decoration of MTs with mutated M1 significantly lower their depolymerization. Scale bar, $20 \mu \mathrm{m}$. Values are mean \pm SEM. ${ }^{* * *} p<0.0001$ ( $t$ test). $n=30$.

repolymerization, and as a result, a restoration of MT levels is observed.

To test the effect of mutated spastin isoforms on MT dynamics, control RFL-6/Tet-On cells and stable trasfected RFL-6 cell lines TRE/M87CY or TRE/M1CY were cultured in medium with $2 \mu \mathrm{g} / \mathrm{ml}$ Dox for $18 \mathrm{~h}$, and then MT fluorescence intensity was measured after $15 \mathrm{~min}$ of treatment with $2 \mu \mathrm{g} / \mathrm{ml}$ nocodazole at $37^{\circ} \mathrm{C}$. As expected, in control cells (outlined in yellow in Fig. 7) that do not express spastins, nocodazole treatment resulted in significant decrease of MT fluorescence intensity compared with cells not treated with nocodazole (e.g., Fig. 2A). We chose the concentration of nocodazole and the duration of treatment to cause significant but not total depolymerization of MTs. Such conditions allowed us to observe whether mutated spastins alter the depolymerization rate, resulting in differences in MT fluorescence intensity in spastinexpressing cells relative to controls. The results of such experiments show that MT loss was significantly increased by the presence of M87 C448Y in nocodazoletreated cells (Fig. $7 B$, outlined in red), indicating that mutated M87 increases the rate of MT depolymerization. However, in cells expressing M87 C448Y spastin below detection levels (Fig. 7B, cells outlined in yellow), no effects on MT depolymerization were observed. The effect of M1 C448Y on the rate of MT depolymerization depended on whether this mutated isoform decorated MT or formed aggregates. As shown in Figure 2D, at moderate expression levels, M1 C448Y decorates a subset of MTs around the nucleus. When such cells (Fig. $7 C$, outlined in red) were treated with nocodazole, the depolymerization of MTs was significantly decreased compared with control nonexpressing cells (Fig. $7 A$, outlined in yellow). Interestingly, however, MTs prevented from depolymerization in M1 C448Y cells were not only the ones around the nucleus, and most of the MTs that did not depolymerize were not visibly decorated with spastin (Fig. 7C).

To further investigate this issue, we used cells transiently transfected with M1 C448Y. In such cells, mutated M1 can be rapidly expressed at high levels and either form aggregates in cytoplasm or decorate MTs (Fig. 7D). The propensity of M1 to form aggregates is most likely the result of the presence of an $\mathrm{N}$-terminal hydrophobic region not present in the M87 isoform. In misfolded proteins, such hydrophobic regions tend to be inappropriately exposed and can interact with similarly exposed hydrophobic regions resulting in homo-aggregate or hetero-aggregate formation. As expected, MTs decorated with mutated M1 spastin (Fig. $7 D$, green arrowhead) were prevented from depolymerization, but MTs in cells expressing aggregated M1 C448Y were efficiently depolymerized. We therefore concluded that to decrease MT depolymerization rate, mutated spastin has to decorate MTs and even very low levels of mutated M1, undetectable with our antibody can still be sufficient (as shown in Fig. 7C). Quantification of the effects of M87 C448Y and M1 C448Y on MT depolymerization is presented in Figure 7E. Removal of nocodazole allowed us to test the effect of mutated spastins on MT repolymerization. Figure $8 \mathrm{~A}$ 


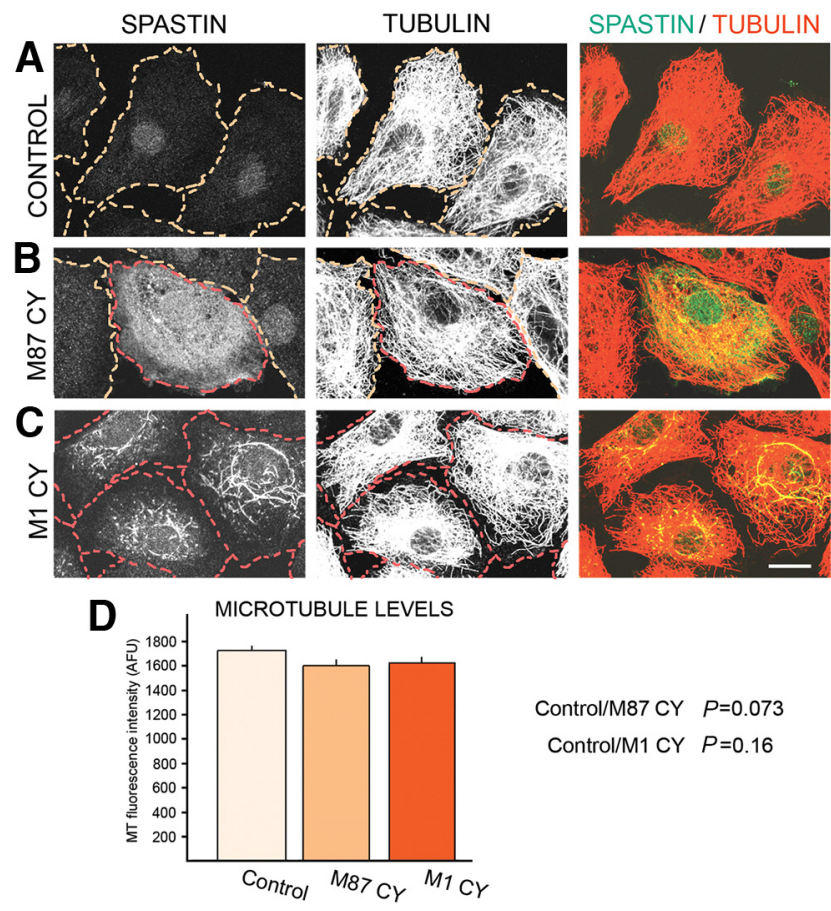

Figure 8. Moderate ectopic expression of mutated spastin isoforms does not affect MT repolymerization. After $15 \mathrm{~min}$ of depolymerization in the presence of $2 \mu \mathrm{g} / \mathrm{ml}$ nocodazole, cells were rinsed and cultured for $20 \mathrm{~min}$ in nocodazole-free medium to allow the repolymerization of MTs. The measurements of fluorescence intensity after staining with anti-tubulin antibody were used to evaluate MT levels. $\boldsymbol{A}$, A full repolymerization of MTs was observed in control nonexpressing cells (outlined in yellow). $\boldsymbol{B}$, MT levels in cells expressing moderate levels of M87 C448Y (outlined in red) were indistinguishable from MT levels in nonexpressing cells (outlined in yellow). C, Moderate levels of M1 (448Y colocalizing with MTs (cells outlined in red) did not affect MT repolymerization. $\boldsymbol{D}$, Quantification of MT levels measured as tubulin fluorescence intensity shows no statistically significant differences between control cells and cells expressing mutated spastin isoforms. Scale bar, $20 \mu \mathrm{m}$. Values are mean $\pm \mathrm{SEM} ; n=30$.

shows the repolymerized MTs in control cells (outlined in yellow), 20 min after nocodazole was removed from culture medium. The level of MTs in control cells measured as MT fluorescence intensity was statistically the same as the MT level in cells expressing moderate level of M87 C448Y (Fig. 8B,D) or moderate levels of M1 C448Y (Fig. 8C,D, spastin-expressing cells outlined in red). It was also noticeable that M87 C448Y is evenly diffuse in the cytoplasm, whereas M1 C448Y colocalizes with MTs. We therefore concluded that spastin levels that affect MT depolymerization do not interfere with MT repolymerization. The quantity of mutated spastins in spinal cords of HSP-SPG4 patients is unknown, but in many neurodegenerative diseases mutated proteins can accumulate. We therefore wished to test whether high levels of mutated spastin isoforms can affect MT repolymerization. In the case of the M87 C448Y, decreased repolymerization was observed only at high levels of expression and, although noticeable, it was not extreme (Fig. 9A; compare MT levels in nonexpressing cells outlined in yellow and M87 C448Y expressing cells outlined in red). The negative effect of aggregated M1 C448Y on MT repolymerization was observed even at moderate expression levels and was profound at high expression levels (Fig. 9B; M1 C448Y expressing cells outlined in red). Interestingly, when MTs were decorated by high levels of M1 C448Y, it not only prevented depolymerization as shown in Figure $7 D$, but also decreased repolymerization (Fig. 9C; expressing cell outlined in red).
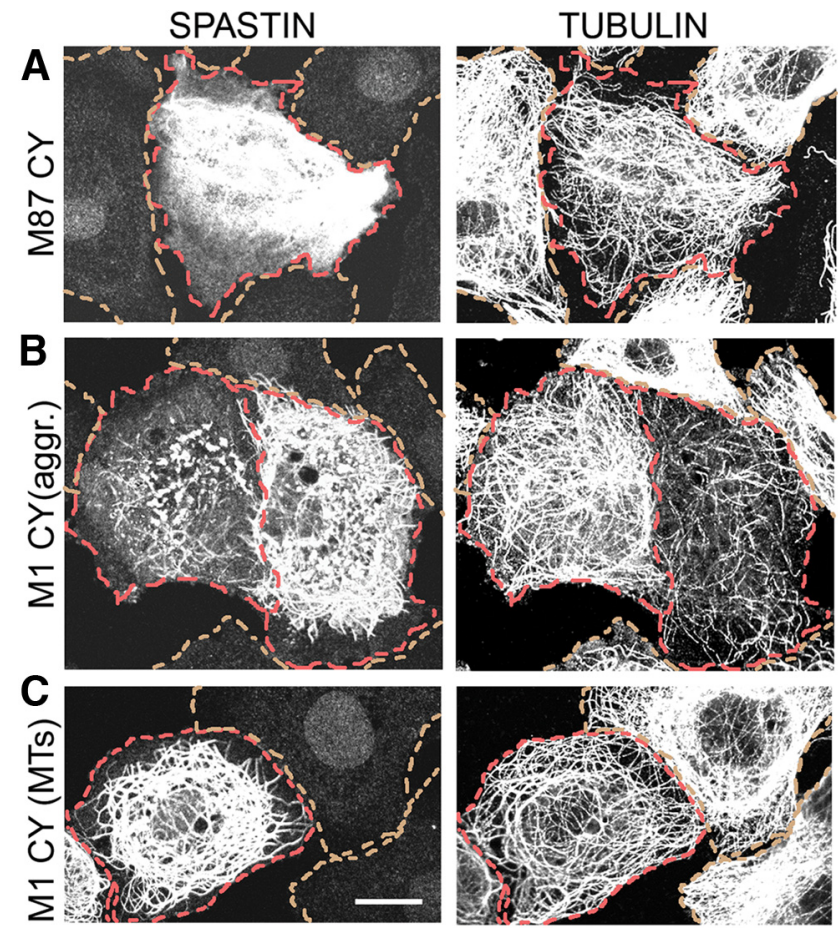

Figure 9. High levels of $\mathrm{C} 448 \mathrm{Y}$ spastin overexpression decrease MT repolymerization. High levels of mutated spastin isoforms were expressed in RFL-6/Tet-0n cells transiently transfected with pTRE/M87CY or PTRE/M1CY and cultured for $18 \mathrm{~h}$ with of $0.5 \mu \mathrm{g} / \mathrm{ml}$ Dox. After $15 \mathrm{~min}$ of depolymerization in the presence of $2 \mu \mathrm{g} / \mathrm{ml}$ nocodazole, cells were rinsed and cultured for 20 min in nocodazole-free medium to allow MT repolymerization. Staining with anti-spastin antibody identified spastin-expressing cells. Tubulin staining was used to evaluate MT levels. $\boldsymbol{A}$, High levels M87 C448Y (cell outlined in red) moderately decreased MT repolymerization compared with nonexpressing cells (outlined in yellow). $\boldsymbol{B}$, In cells expressing aggregated M1 (448Y (outlined in red), decrease of MT repolymerization correlates directly with the levels of M1 C448Y expression. C, High levels of M1 C448Y decorating MTs (in cell outlined in red) can also decrease repolymerization. Scale bar, $20 \mu \mathrm{m}$.

To test how mutated spastin isoforms affect individual MTs, we recorded polymerization and depolymerization of MTs in living cells. RFL-6 cells were cotransfected with a bicistronic pIRES2 DsRed-Express2 vector carrying M87 C448Y or M1 C448Y cDNA and with the tdEos-tubulin-C-18. Expression of RFP allowed identification of cells synthesizing untagged M1 C448 or M87 C448. Control cells were cotransfected with pIRES2 DsRed-Express2 and tdEos-tubulin-C-18 vector. The differences between MT polymerization and depolymerization in control and mutated spastin-expressing cells became the most clearly pronounced after $120 \mathrm{~s}$. Although the expression of mutated spastins did not significantly change the number of MTs undergoing polymerization or depolymerization compared with the control, a significant increase in the length of growth or shortening of the individual MT (Fig. 10, red and blue tracings, respectively) was observed in cells expressing M87 C448Y or aggregated M1 C448Y. In control cells, the average increase of the individual MT length resulting from polymerization over $120 \mathrm{~s}$ was $2.5 \pm$ $0.33 \mu \mathrm{m}$ compared with $3.6 \pm 0.34 \mu \mathrm{m}$ in cells expressing M87 C448 $(p=0.0136)$ and $3.7 \pm 0.44 \mu \mathrm{m}$ in cells expressing M1 C448 $(p=0.0336)$. The average decrease of the individual MT length resulting from depolymerization over $120 \mathrm{~s}$ was $3.6 \pm 0.53$ $\mu \mathrm{m}$ in control cells compared with $6.1 \pm 0.89 \mu \mathrm{m}$ in cells expressing M87 C448 ( $p=0.0352)$, and $5.3 \pm 0.057 \mu \mathrm{m}$ in cells expressing M1 C448 ( $p=0.043)$. These results help to explain the greater loss of MTs in the presence of nocodazole and a good recovery of 


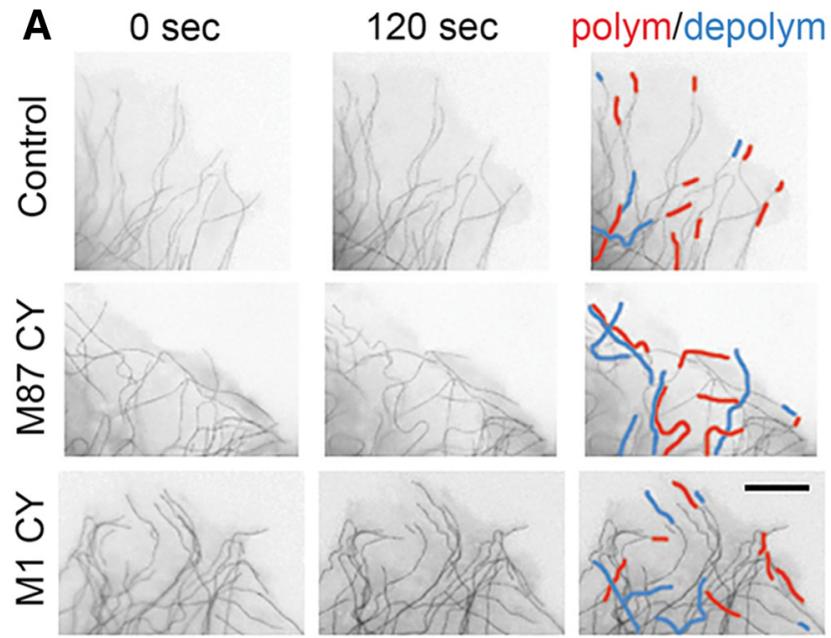

B Polymerization Depolymerization

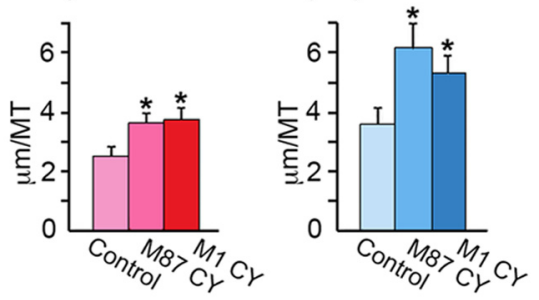

Figure 10. Expression of mutated spastin isoforms affects the length of growth (polymerization) and shortening (depolymerization) of individual MTs in live cells. RFL-6 cells were cotransfected with M87 C448Y or M1 C448Y CDNA cloned into a bicistronic pIRES2 DsRedExpress 2 vector and with the $t$ Enos-tubulin-C-18. Fluorescent microscopic images of MTs in live cells were subjected to the "invert" function in AdobePhotoshop to improve contrast. $\boldsymbol{A}$, The expression of M87 (448Y or aggregated M1 (448 resulted in increased growth (red tracings) and shortening (blue tracings) of individual MTs over $120 \mathrm{~s}$, compared with nonexpressing controls. B, Quantification revealed statistically significant increase in polymerization and depolymerization of MTs in cells expressing M87 C448Y or aggregated M1 C448Y. Values are mean \pm SEM. Scale bar, $5 \mu \mathrm{m}$.

MTs after nocodazole removal observed in cells expressing M87 C448Y or aggregated M1 C448Y (Figs. 7 and 8). By contrast, polymerization and depolymerization (Fig. $11 B, C$, red and blue tracings, respectively) of individual MTs decorated with M1 C448 were inhibited compared with the region in the same cell where MTs were not decorated with mutated M1 (Fig. 11C). Statistical analysis revealed that in 120 s only $28.4 \pm 6.3 \%$ of MTs decorated with M1 C448Y spastin underwent polymerization or depolymerization compared with $74 \pm 0.35 \%$ of MTs that were not decorated with mutated M1 $(p=0.002)$. This result shows that decoration with mutated M1 indeed stabilizes MTs and confirms the observation indicated by the nocodazole experiment (Fig. $7 C, D)$. We, however, also observed much greater variation in dynamics of MTs decorated with M1 C448Y. Over 120 s, 71$76 \%$ of individual MTs observed in control cells as well as in cells expressing M87 C448Y or aggregated M1 C448Y consistently polymerized or depolymerized, whereas the percentage of dynamic MTs decorated with M1 C448Y could be as low as $18 \%$ and as high as $40 \%$, depending most likely on the extent of decoration.

Collectively, these results indicate that missense spastin mutations can directly affect MT dynamics in an isoform-dependent fashion that is also independent of spastin's normal MT-severing activity.
A Microtubules

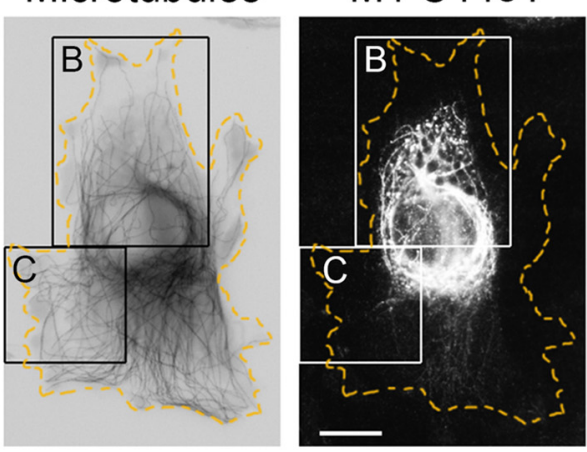

B

$0 \mathrm{sec}$.

$120 \mathrm{sec}$.
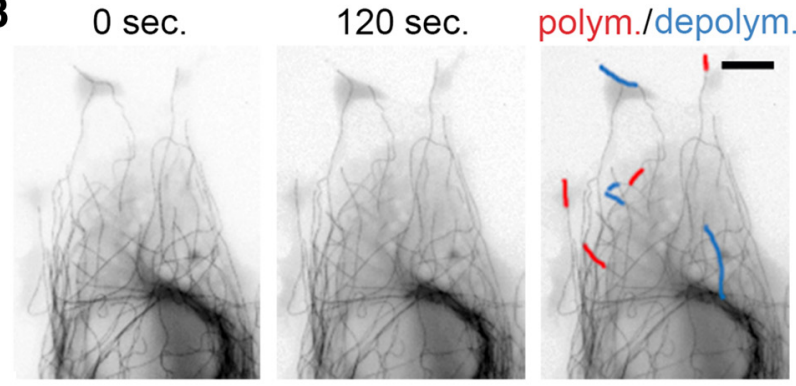

C
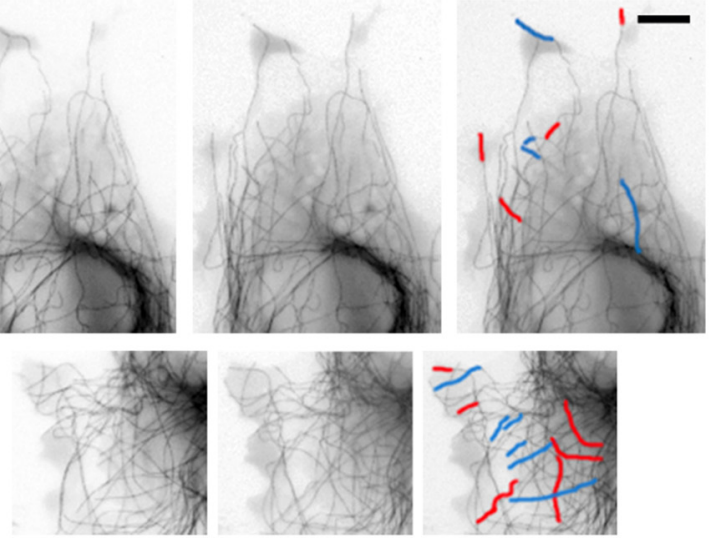

Figure 11. MTs decorated with M1 (448Y are less dynamic. $\boldsymbol{A}$, Postmortem immunostaining with anti-spastin antibody reveled a subset of MTs decorated with mutated M1 in the boxed area $B$ but not in the boxed area C in RFL- 6 cell cotransfected with tdEos-tubulin-C-18 and M1 C448Y. B, C, Enlarged boxed areas B and C. Polymerization and depolymerization of MTs decorated with $\mathrm{M} 1 \mathrm{C} 448 \mathrm{Y}$ shown in $B$ are decreased relative to polymerization and depolymerization of MTs not decorated with M1 C448Y shown in C. Scale bars: $A, 10 \mu \mathrm{m} ; \boldsymbol{B}, \boldsymbol{C}, 5 \mu \mathrm{m}$.

\section{Discussion}

The haploinsufficiency model for HSP-SPG4 posits that inactivation of one of the spastin alleles results in spastin levels too low for adequate MT severing. In theory, this would lead to diminished MT severing, which would in turn lead to abnormal MT stabilization as the underlying mechanism of the disease (Bürger et al., 2000; Fonknechten et al., 2000; Lindsey et al., 2000; Sherwood et al., 2004; Trotta et al., 2004; Orso et al., 2005; Wood et al., 2006; Fassier et al., 2013). However, such a scenario fails to adequately explain axonal degeneration in HSP-SPG4 patients (Yip et al., 2003; Solowska et al., 2010). In most neurodegenerative diseases, expression of neurotoxic proteins is a causative factor, and our earlier studies suggested that mutations in SPG4 might result in neurotoxic proteins (Solowska et al., 2008).

SPG4 open reading frame has two start codons. The presence of a weak Kozak's sequence at the first start codon leads to leaky scanning of the first AUG, and hence preferred initiation of translation at the second AUG, which has a better Kozak's sequence. As a result, a $68 \mathrm{kDa}$ isoform called $\mathrm{M} 1$ and a $60 \mathrm{kDa}$ isoform called M87 can be synthesized simultaneously but at different levels (Kozak, 2002; Claudiani et al., 2005; Solowska et al., 2008). In rodents, the shorter isoform is the predominant spastin isoform in all tissues at all stages of development analyzed, whereas M1 is only detectably present in adult spinal cord (Solowska et al., 2008). Similarly, the analysis of spastin expression in adult human CNS revealed the presence of M87 both in spinal cord and 
cerebral cortex, whereas significant levels of M1 were detected only in spinal cord and not in brain (Solowska et al., 2010). These findings raised the possibility that mutated M1 might be more relevant than mutated M87 to the degeneration of corticospinal tracts axons observed in HSP-SPG4. Here we endeavored, for the first time, to test the functional properties of untagged mutated human spastin isoforms. We separately expressed human M1 and M87 spastins carrying the same C448Y disease-related mutation that inhibits MT-severing activity (Hazan et al., 1999; Fonknechten et al., 2000). The expression of either M1 C448Y or M87 $\mathrm{C} 448 \mathrm{Y}$ in primary cortical neurons diminished neurite outgrowth, but the effect of M1 C448Y was notably more severe. Similarly, in transgenic Drosophila, motor defects caused by individually expressed M1 C448Y were more severe than caused by M87 C488Y, and climbing activity showed a greater progressive decline in flies expressing M1 C448Y than M87 C448Y.

The Drosophila phenotype was similar to that of flies with spastin selectively eliminated from the CNS by tissue-specific Dspastin RNAi (Orso et al., 2005), raising the possibility that the defects we observed resulted from mutated spastin proteins acting in dominant-negative fashion. However, we found that the coexpression of either of the mutated isoforms did not lower MT-severing by WT M87 spastin. We therefore concluded that the phenotypic defects observed in cultured neuronal cells and transgenic Drosophila were unlikely to be caused by dominantnegative lowering of MT-severing by mutated spastins ectopically expressed in WT background but can be better explained by toxic gain of function.

The greater toxicity of mutated M1 combined with the elevated expression of this isoform in adult spinal cord might provide some explanation for the specific degeneration of axons in corticospinal tracts. However, the translation of endogenous M1 spastin is tightly controlled, such that endogenous levels are low compared with our experimental levels. That may explain why toxic effects of mutated $\mathrm{M} 1$ are not observed during development and (in most cases) early in the patient's life. In our experimental setting where the expression levels of each mutated spastin isoform were controlled by identical promoter and Kozak's sequence, mutated M1 seemed to be more stable and accumulate to higher levels than mutated M87, and we suspect that this contributed to the higher level of toxicity of M1 C448Y compared with M87 C448Y. It remains unknown whether mutated M1 spastin accumulates in CNS of HSP-SPG4 patients, although we have reported evidence for this in one patient (Solowska et al., 2010).

Mutated M1 expressed at moderate levels decorated MTs in both non-neuronal and neuronal cells, whereas M87 with the same mutation remained diffuse in the cytoplasm. Therefore, it seems that MT decoration requires not only the presence of the MIT and MTBD domains that are identical in M1 C448Y and M87 C448Y, but also the presence of the hydrophobic 86 amino acids N-terminal domain specific to M1. The different ability of the two mutated spastin isoforms to decorate MTs correlated with their effects on MT dynamics. Experiments in which nocodazole was used showed that MTs decorated with mutated M1 were resistant to depolymerization, whereas the presence of $\mathrm{cy}$ toplasmic M87 C448Y or aggregated M1 C448Y significantly intensified MT depolymerization. High levels of either mutated M1 or mutated M87 decreased MT repolymerization. Live-cell imaging revealed that these effects may result from greater increases or decreases in the length of individual MTs at a given time period in cells expressing mutated spastins compared with nonexpressing control cells. These results indicate that at least some mutated spastin proteins could affect MT dynamics in HSP-SPG4 pa- tients. Interestingly, mutated M87 might lessen the impact of the lost severing activity by increasing MT dynamics, particularly early in development when expression levels of this isoform are the highest. Accumulation of mutated M1 isoform, however, would exaggerate the effects of the lost MT-severing activity. Because the expression levels of $\mathrm{M} 1$ are very low in vivo, the ill effects of overstabilization of MTs by mutated M1 would not be immediately obvious in HSP-SPG4 patients. This would presumably worsen with age and may account for the progressive degeneration.

The question remains whether other mutations found in SPG4 result in expression of spastins that affect MT dynamics. Our experiments indicated that it was the decoration of MTs with M1 C448Y that stabilizes MT, and such MT decoration has been reported for a number of spastins carrying missense mutations in the AAA domain. Some of these mutations are located, like the C448Y mutation, in the pore loop 2 affecting the interaction of spastin with tubulin tails and thereby prevent MT-severing (White et al., 2007), whereas others, such as K388R (Errico et al., 2002), N386K or I344K (Evans et al., 2005), and R424G (McDermott et al., 2003), are located outside of the pore loops. As the MT decoration reported by others was observed in cells transfected with constructs expressing both spastin isoforms simultaneously, it was previously assumed that both mutated isoforms and not just mutated M1 interact with a subset of MTs around nucleus. Obviously, however, the presence of mutated M87 does not prevent MT decoration by mutated M1. As WT M1 does not decorate MTs (Solowska et al., 2010), we propose that missense mutations in the AAA domain of the M1 isoform that inactivate MT-severing also allow mutated M1 to decorate and stabilize MTs. It has been shown that such abnormal interaction of the mutant spastin with MTs can disrupt organelle transport and thereby might contribute to axonal degeneration in human patients (McDermott et al., 2003). If this is the case, our studies suggest that it is the M1 isoform that is responsible.

In contrast to mutated M1 decorating MTs, mutated M87 might increase MT dynamics and therefore be beneficial in situations when MT-severing is compromised. Indeed, it was reported that expression of mutated human spastin K388R increased the eclosion rate in spastin null Drosophila (Du et al., 2010). On the other hand, expression of mutated M87 in WT background might result in abnormal destabilization of MTs. If true, MT-stabilizing drugs should be helpful, and indeed, it was shown that low concentrations of vinblastine attenuated the effects of ectopically expressed mutated K467R Dspastin in transgenic Drosophila (Orso et al., 2005). The increased MT depolymerization we observed in cells expressing either mutated M87 or mutated M1 that does not decorate MTs but forms aggregates might, over time and in combination with lower rate of repolymerization, cause MT loss. Such an outcome would be opposite to the one resulting from an excessive MT stabilization, and indeed, a decrease in tubulin staining has been reported in corticospinal tracts of HSP-SPG4 patients (Wharton et al., 2003). It is therefore unclear how much of a role stabilization of MTs decorated by mutated M1 plays in the etiology of HSP-SPG4, particularly because spastins carrying truncating mutations that are more common than missense mutations do not have domains that enable interaction with MTs. Our unpublished observations indicate that truncated M1 isoforms indeed do not decorate MTs, but similarly to M1 carrying missense mutations, do form aggregates. How such aggregated spastins affect neuronal vitality remains unknown, but the results of our current studies indicate that the detailed role of mutated spastin isoforms in the etiology 
of HSP-SPG4 is likely to be complex. Even so, documentation of the effects on MTs may enable straightforward clinical approaches for offsetting these effects with available pharmacologic treatments, thereby ameliorating at least some of the debilitating symptoms of the disease.

\section{References}

Allison R, Lumb JH, Fassier C, Connell JW, Ten Martin D, Seaman MN, Hazan J, Reid E (2013) An ESCRT-spastin interaction promotes fission of recycling tubules from the endosome. J Cell Biol 202:527-543. CrossRef Medline

Baas PW, Ahmad FJ (2013) Beyond taxol: microtubule-based treatment of disease and injury of the nervous system. Brain 136:2937-2951. CrossRef Medline

Baas PW, Vidya Nadar C, Myers KA (2006) Axonal transport of microtubules: the long and short of it. Traffic 5:490-498.

Brand AH, Perrimon N (1993) Targeted gene expression as a means of altering cell fates and generating dominant phenotypes. Development 118: 401-415. Medline

Bürger J, Fonknechten N, Hoeltzenbein M, Neumann L, Bratanoff E, Hazan J, Reis A (2000) Hereditary spastic paraplegia caused by mutations in the SPG4 gene. Eur J Hum Genet 8:771-776. CrossRef Medline

Claudiani P, Riano E, Errico A, Andolfi G, Rugarli EI (2005) Spastin subcellular localization is regulated through usage of different translation start sites and active export from the nucleus. Exp Cell Res 30:358-369. CrossRef Medline

Du F, Ozdowski EF, Kotowski IK, Marchuk DA, Sherwood NT (2010) Functional conservation of human spastin in a Drosophila model of autosomal dominant-hereditary spastic paraplegia. Hum Mol Genet 19: 1883-1896. CrossRef Medline

Errico A, Ballabio A, Rugarli EI (2002) Spastin, the protein mutated in autosomal dominant hereditary spastic paraplegia, is involved in microtubule dynamics. Hum Mol Genet 11:153-163. CrossRef Medline

Evans KJ, Gomes ER, Reisenweber SM, Gundersen GG, Lauring BP (2005) Linking axonal degeneration to microtubule remodeling by spastinmediated microtubule severing. J Cell Biol 16:599-606. CrossRef Medline

Fassier C, Tarrade A, Peris L, Courageot S, Mailly P, Dalard C, Delga S, Roblot N, Lefèvre J, Job D, Hazan J, Curmi PA, Melki J (2013) Microtubuletargeting drugs rescue axonal swellings in cortical neurons from spastin knockout mice. Dis Model Mech 6:72-83. CrossRef Medline

Fonknechten N, Mavel D, Byrne P, Davoine CS, Cruaud C, Bönsch D, Boentsch D, Samson D, Coutinho P, Hutchinson M, McMonagle P, Burgunder JM, Tartaglione A, Heinzlef O, Feki I, Deufel T, Parfrey N, Brice A, Fontaine B, Prud'homme JF, et al. (2000) Spectrum of SPG4 mutations in autosomal dominant spastic paraplegia. Hum Mol Genet 9:637-644. CrossRef Medline

Hazan J, Fonknechten N, Mavel D, Paternotte C, Samson D, Artiguenave F, Davoine CS, Cruaud C, Dürr A, Wincker P, Brottier P, Cattolico L, Barbe V, Burgunder JM, Prud'homme JF, Brice A, Fontaine B, Heilig B, Weissenbach J (1999) Spastin, a new AAA protein, is altered in the most frequent form of autosomal dominant spastic paraplegia. Nat Genet 23: 296-303. CrossRef Medline

Kasher PR, De Vos KJ, Wharton SB, Manser C, Bennett EJ, Bingley M, Wood JD, Milner R, McDermott CJ, Miller CC, Shaw PJ, Grierson AJ (2009) Direct evidence for axonal transport defects in a novel mouse model of mutant spastin-induced hereditary spastic paraplegia (HSP) and human HSP patients. J Neurochem 110:34-44. CrossRef Medline

Kozak M (2002) Pushing the limits of the scanning mechanism for initiation of translation. Gene 299:1-34. CrossRef Medline

Leal SM, Neckameyer WS (2002) Pharmacological evidence for GABAergic regulation of specific behaviors in Drosophila melanogaster. J Neurobiol 50:245-261. CrossRef Medline

Le Bourg E, Lints FA (1992) Hypergravity and aging in Drosophila melanogaster: 4. Climbing activity. Gerontology 38:59-64. Medline

Lindsey JC, Lusher ME, McDermott CJ, White KD, Reid E, Rubinsztein DC, Bashir R, Hazan J, Shaw PJ, Bushby KM (2000) Mutation analysis of the spastin gene (SPG4) in patients with hereditary spastic paraparesis. J Med Genet 37:759-765. CrossRef Medline
McDermott CJ, Grierson AJ, Wood JD, Bingley M, Wharton SB, Bushby KM, Shaw PJ (2003) Hereditary spastic paraparesis: disrupted intracellular transport associated with spastin mutation. Ann Neurol 6:748-759. CrossRef Medline

Melicharek DJ, Ramirez LC, Singh S, Thompson R, Marenda DR (2010) Kismet/CHD7 regulates axon morphology, memory and locomotion in a Drosophila model of CHARGE syndrome. Hum Mol Genet 19:42534264. CrossRef Medline

Orso G, Martinuzzi A, Rossetto MG, Sartori E, Feany M, Daga A (2005) Disease-related phenotypes in a Drosophila model of hereditary spastic paraplegia are ameliorated by treatment with vinblastine. J Clin Invest 115:3026-3034. CrossRef Medline

Riano E, Martignoni M, Mancuso G, Cartelli D, Crippa F, Toldo I, Siciliano G, Di Bella D, Taroni F, Bassi MT, Cappelletti G, Rugarli EI (2009) Pleiotropic effects of spastin on neurite growth depending on expression levels. J Neurochem 108:1277-1288. CrossRef Medline

Roll-Mecak A, Vale RD (2005) The Drosophila homologue of the hereditary spastic paraplegia protein, spastin, severs and disassembles microtubules. Curr Biol 15:650-655. CrossRef Medline

Roll-Mecak A, Vale RD (2008) Structural basis of microtubule severing by the hereditary spastic paraplegia protein spastin. Nature 45:363-367. CrossRef Medline

Sherwood NT, Sun Q, Xue M, Zhang B, Zinn K (2004) Drosophila spastin regulates synaptic microtubule networks and is required for normal motor function. PLoS Biol 2:e429. CrossRef Medline

Shoukier M, Neesen J, Sauter SM, Argyriou L, Doerwald N, Pantakani DV, Mannan AU (2009) Expansion of mutation spectrum, determination of mutation cluster regions and predictive structural classification of SPAST mutations in hereditary spastic paraplegia. Eur J Hum Genet 17:187-194. CrossRef Medline

Solowska JM, Morfini G, Falnikar A, Himes BT, Brady ST, Huang D, Baas PW (2008) Quantitative and functional analyses of spastin in the nervous system: implications for hereditary spastic paraplegia. J Neurosci 28 : 2147-2157. CrossRef Medline

Solowska JM, Garbern JY, Baas PW (2010) Evaluation of loss-of-function as an explanation for SPG4-based hereditary spastic paraplegia. Hum Mol Genet 19:2767-2779. CrossRef Medline

Tarrade A, Fassier C, Courageot S, Charvin D, Vitte J, Peris L, Thorel A, Mouisel E, Fonknechten N, Roblot N, Seilhean D, Diérich A, Hauw JJ, Melki J (2006) A mutation of spastin is responsible for swellings and impairment of transport in a region of axon characterized by changes in microtubule composition. Hum Mol Genet 15:3544-3558. CrossRef Medline

Trotta N, Orso G, Rossetto MG, Daga A, Broadie K (2004) The hereditary spastic paraplegia gene, spastin, regulates microtubule stability to modulate synaptic structure and function. Curr Biol 14:1135-1147. CrossRef Medline

Wharton SB, McDermott CJ, Grierson AJ, Wood JD, Gelsthorpe C, Ince PG, Shaw PJ (2003) The cellular and molecular pathology of the motor system in hereditary spastic paraparesis due to mutation of the spastin gene. J Neuropathol Exp Neurol 62:1166-1177. Medline

White SR, Evans KJ, Lary J, Cole JL, Lauring B (2007) Recognition of C-terminal amino acids in tubulin by pore loops in Spastin is important for microtubule severing. J Cell Biol 176:995-1005. CrossRef Medline

Wood JD, Landers JA, Bingley M, McDermott CJ, Thomas-McArthur V, Gleadall LJ, Shaw PJ, Cunliffe VT (2006) The microtubule-severing protein Spastin is essential for axon outgrowth in the zebrafish embryo. Hum Mol Genet 15:2763-2771. CrossRef Medline

Yang H, Ganguly A, Cabral F (2010) Inhibition of cell migration and cell division correlates with distinct effects of microtubule inhibiting drugs. J Biol Chem 285:3242-3250. CrossRef Medline

Yip AG, Dürr A, Marchuk DA, Ashley-Koch A, Hentati A, Rubinsztein DC, Reid E (2003) Meta-analysis of age at onset in spastin-associated hereditary spastic paraplegia provides no evidence for a correlation with mutational class. J Med Genet 40:e106. CrossRef Medline

Yu W, Solowska JM, Qiang L, Karabay A, Baird D, Baas PW (2005) Regulation of microtubule severing by katanin subunits during neuronal development. J Neurosci 25:5573-5583. CrossRef Medline 